\title{
Article \\ Optimization and Analysis of Electric Vehicle Operation with Fast-Charging Technologies
}

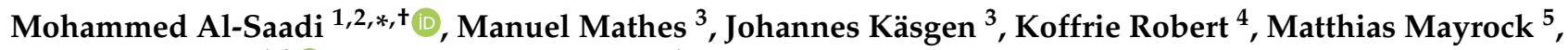 \\ Joeri Van Mierlo ${ }^{1,2}$ and Maitane Berecibar ${ }^{1}$ \\ 1 MOBI Research Group, Vrij Universiteit Brussel (VUB), Pleinlaan 2, 1050 Elsene, Belgium; \\ Joeri.Van.Mierlo@vub.be (J.V.M.); Maitane.Berecibar@vub.be (M.B.) \\ 2 Flanders Make, 3001 Heverlee, Belgium \\ 3 Fraunhofer-Institut für Betriebsfestigkeit und Systemzuverlässigkeit LBF, Bartningstraße 47, \\ 64289 Darmstadt, Germany; manuel.mathes@lbf.fraunhofer.de (M.M.); \\ johannes.kaesgen@lbf.fraunhofer.de (J.K.) \\ 4 Nederlandse organisatie voor Toegepast Natuurwetenschappelijk Onderzoek TNO, Helmond Automotive \\ Campus, Postbus 756, 5700 AT Helmond, The Netherlands; robert.koffrie@tno.nl \\ 5 Man Truck \& Bus SE, Dachauer Straße 667, 80995 Munich, Germany; Matthias.Mayrock@man.eu \\ * Correspondence: mohammed.al-saadi@vub.be \\ + Manager of the ASSURED project.
}

check for

updates

Citation: Al-Saadi, M.; Mathes, M.; Käsgen, J.; Robert, K.; Mayrock, M.; Mierlo, J.V.; Berecibar, M. Optimization and Analysis of Electric Vehicle Operation with Fast-Charging Technologies. World Electr. Veh. J. 2022, 13, 20 https://doi.org/10.3390/ wevj13010020

Academic Editor: Hui Yang

Received: 1 December 2021

Accepted: 10 January 2022

Published: 13 January 2022

Publisher's Note: MDPI stays neutral with regard to jurisdictional claims in published maps and institutional affiliations.

Copyright: (C) 2022 by the authors. Licensee MDPI, Basel, Switzerland. This article is an open access article distributed under the terms and conditions of the Creative Commons Attribution (CC BY) license (https:// creativecommons.org/licenses/by/ $4.0 /)$.

\begin{abstract}
This work presents three demos, which include Electric Buses (EBs) from four various brands with lengths of $12 \mathrm{~m}$ and $18 \mathrm{~m}$ and an Electric Truck (E-truck) for refuse collection. The technical operation of these EVs were analyzed to implement further operational cost optimization on the demo vehicles. The Electric Vehicles (EVs) were tested against superfast-charging solutions based on Pantograph (Type A \& Type B) on the route lines (and depots) and based on Combined Charging System Type 2 (CCS2, Combo2) from various brands to validate the interoperability among several vendors and support further EV integration with more affordable solutions. The optimization includes the calculation of the EBs' consumption at various seasons and under various operating conditions in order to use optimum battery system design, heating system, optimum EB fleet operation and size and to find the charging solutions properly. The results showed that the EB consumption increases in some cases by $64.5 \%$ in wintertime due to heating systems, and the consumption in urban areas is more than that on the route lines outside cities. In the E-truck demo, where the electric heater was replaced with a heat-pump to optimize the energy consumption, it was found that the consumption of the heat-pump is about half of the electric heater under certain operating conditions. Under strict EB schedule, Pantograph charging solutions with power ratings of 300-600 kW have been adopted to charge the batteries of the EBs within 4-10 min. In order to minimize the cumulative costs of energy, (pantograph) charging infrastructure depreciation and battery degradation, as well as depot charging (at the bus operator's depot), was adopted with a power level of 50-350 kW based on CCS2 and pantograph.
\end{abstract}

Keywords: electric vehicles; medium-duty electric vehicles; heavy-duty electric vehicles; EBs; E-truck; fast-charging; opportunity charging; depot charging; battery system

\section{Introduction}

Climate change has brought a significant concern over the past few decades due to its impact on communities worldwide, which increases day in, day out. The trams, metro, and trains are already electrified in most cities in Europe and worldwide. Efforts are now focused on the electrification of diesel buses. As well as emitting no $\mathrm{CO}_{2}$, Electric Buses (EBs) make much less noise and have less operational cost than the diesel-powered ones. Public transportation means could play a vital role in minimizing $\mathrm{CO}_{2}$ emissions as they have average operating hours of around 16-20 h per day, compared with private cars, which have around $1-2 \mathrm{~h}$ per day $[1,2]$. 


\subsection{Literature Review}

Nowadays, the vast majority of Heavy-Duty (HD) vehicles in operation within Europe are propelled by Internal Combustion Engine (ICE), which typically runs on diesel, as this is the most affordable and convenient energy carrier. So far, only a negligible number of low- and zero-emission trucks are in operation. The European truck manufacturers were set a target to reach carbon neutrality in road freight transport by 2050 at the latest [3,4]. In China [5], Shenzhen city moved to $100 \%$ EB integration, with chargers with a power level of $750 \mathrm{~kW}$ and EB mileage of about $250 \mathrm{~km}$.

The chargers must supply the EBs with enough energy to reach their destinations. Therefore, it is essential to identify the charger's power and EB mileage, which is based mainly on EB consumption. The EB consumption depends on several factors, such as load, weather (heating system on/off), traffic, city terrain, etc. For an $18 \mathrm{~m} \mathrm{~EB}$, the average energy consumption for 10 months of operation is around $1.63 \mathrm{kWh} / \mathrm{km}$, and for a $12 \mathrm{~m} \mathrm{~EB}$, it is around $1.15 \mathrm{kWh} / \mathrm{km}$. In temperatures of $15-19^{\circ} \mathrm{C}$, the $18 \mathrm{~m}$ EB consumes, on average, $1.35 \mathrm{kWh} / \mathrm{km}$, whereas the $12 \mathrm{~m}$ EB consumes $0.99 \mathrm{kWh} / \mathrm{km}$ [6]. An $18.75 \mathrm{~m}$ Trolley bus demo, Ikarus-Škoda Tr187.2, was launched in Budapest, Hungary, with a battery capacity of $80 \mathrm{kWh}$. The trolley bus ran on a route called $77 \mathrm{~A}$, where the round trip was $13.2 \mathrm{~km}$, and the needed distance of the battery mode was $9.2 \mathrm{~km}$. In battery mode, taking into consideration severe terrain properties and weather conditions, with the air-conditioning or heating was switched on, it was found that when the vehicle had no passenger load, it could run for around $20 \mathrm{~km}$. When the vehicle had full passenger load, it could run for about $7 \mathrm{~km}$. Furthermore, the vehicle is considered to use only $33 \mathrm{kWh}$ out of $81 \mathrm{kWh}$ to ensure long battery life [2]. In [7], an energy management system was developed to optimize the auxiliary consumption of the EB fleet; the system is able to be monitored, accessed, and controlled online.

The diesel buses are more financially affordable than the electric ones, which makes the work and support of the various stakeholders' indispensable in reaching the goal of worldwide usage of EBs. It was found that more EBs than diesel buses are needed, which increases the fleet size and cost. In [8], a study was carried out to size the charging systems compared to the battery sizes on the vehicles and to work out the number of EBs required on the route line to investigate the feasibility of replacing the diesel ones. The Use Cases (UCs) are Mercedes-Benz eCitaro EBs, which are normally produced with lithium-ion battery capacities of 150, 200, or $250 \mathrm{kWh}$. These buses are equipped with CSS2 with the potential ability to adopt the pantograph system, which is sold as a piece of special equipment. The test route line $(7.9 \mathrm{~km})$ is between Porto Vado and Via Alessandria (Sovana, Italy), with a total estimated energy consumption of $40.6 \mathrm{kWh}$ for the round trip. It was found that two EBs with a battery capacity of 250 or $200 \mathrm{kWh}$ can cover the operation of one diesel bus with three chargers in the depot with a power capability of $43 \mathrm{kWh}$. With less battery capacity, $150 \mathrm{kWh}$, three EBs are needed to cover the operation of one diesel bus. However, all the buses need to stop at Porto Vado station for some minutes, this time could be used to charge the EBs with opportunity charging. It was found that with an opportunity charging of at least $300 \mathrm{~kW}$, one EB is needed for each diesel bus. The findings are summarized in Table 1.

Table 1. Charging system sizing against EBs size.

\begin{tabular}{llcc}
\hline & Battery Capacity & $\begin{array}{c}\text { Required EBs } \\
\text { (Diesel Buses) }\end{array}$ & $\begin{array}{c}\text { Required EBs } \\
\text { (Diesel Buses) }\end{array}$ \\
\hline Case 1 & $250 \mathrm{kWh}$ & $6(3)$ & $3(3)$ \\
\hline Case 2 & $200 \mathrm{kWh}$ & $6(3)$ & $3(3)$ \\
\hline Case 3 & $150 \mathrm{kWh}$ & $9(3)$ & $3(3)$ \\
\hline $\begin{array}{l}{ }^{*} \text { With CCS2 of } 43 \mathrm{~kW} \text { at the depot. }{ }^{* *} \text { With one opportunity charging of at least 300 } \mathrm{kW} \text { on the route line and } \\
\text { at depot. }\end{array}$
\end{tabular}




\subsection{Research Gap}

It is worth mentioning that in interoperability tests carried out between Electric Vehicle Supply Equipment (EVSE) brands and HD-EV brands, it is quite common to experience some interoperability issues. Those issues typically originate from different interpretations of the standards, from which the most issues by far arise due to different interpretations of communication protocols.

In [9], a study carried out aims to support the application and promotion of the EB through reducing the fleet size, empty driving mileage, and charging facility. A total cost of 544 EB trips with tasks was declined by $19.6 \%$. Although, the average empty driving mileage rise by roughly $20 \%$, the number of EBs and the number of charging points declined by $19.7 \%$ and $33.3 \%$, respectively. The cost of raising the empty driving mileage was brought down by reducing the number of EBs and charging facilities. The long operating time of EBs requires a large storage system (about $300 \mathrm{kWh}$ ) to drive without any charging stops all day. The huge battery weight increases the vehicle's Total Cost of Ownership (TCO) and the operational costs due to an increase in the consumption because of the huge battery weight. Here, the opportunity charging solutions can solve these issues and fast-charge the EBs when they are equipped with low battery capacity. In order to decrease (or maintain) the number of EBs in operation on the route line and maintain the EBs' operation effectively, the targeted SoC must be achieved within around 5-10 min. In the Graz demo, six EBs are operating on a route simultaneously. Therefore, at the 'end-stop', an EB arrives every $10 \mathrm{~min}$ and (depending on traffic) a few minutes are left before it has to leave again. This time (0-5 min) could be used as a 'charging-window'. At the $10 \mathrm{~min}$ end stop, assuming a 2 min charging window (depending on traffic, the actual duration of the end stop may vary; hence, a 2 min minimum is assumed for charging), a $540 \mathrm{~kW}$ of average power is needed to transfer $18 \mathrm{kWh}$ of energy [10]. Such a power level has not yet been achieved by the opportunity charging technologies in most of the previous work, a max power of $300 \mathrm{~kW}$ was achieved in [8], as mentioned in Table 1. Furthermore, the absence of interoperability among various venders of EBs and chargers burden the bus operators with more TCO and operational costs, which has not been investigated by the previous works.

It was found that the power consumption of the auxiliary equipment, including the electric heating, has a great impact on the consumption of EVs. The optimal consumption of a $12 \mathrm{~m} \mathrm{~EB}$ is $0.8 \mathrm{kWh} / \mathrm{km}$ at $20^{\circ} \mathrm{C}$ (without heating) with not much traffic. While the same EB operating in the winter at $-10^{\circ} \mathrm{C}$ can reach a consumption of $2.3-2.5 \mathrm{kWh} / \mathrm{km}$ with the electric heating turned on [6,7]. A few works have investigated the impact of the electric heating on the total vehicle consumption and optimization of the EVs' mileage using the Range Extender (REx). It was proven that using a Heating and Ventilation Air Conditioning (HVAC) system instead of an electrical system could optimise the energy consumption of the vehicles.

\subsection{Contribution}

Securing interoperability between the EVs' charging infrastructure is one of the success factors that will impact the widespread use of electric vehicles in general and EBs in particular and will require special cooperation between the EBs' and chargers' manufacturers. Several projects worldwide examine various solutions for the charging opportunities, e.g., conductive and inductive power transfer (IPT) [2]. In this work, EBs and fast-chargers from various venders were developed, the interoperability between the EBs and fastchargers were tested.

The objective of the charging solution test is to ensure the acceptability of the solutions developed within the ASSURED project, primarily the interoperability of the charging solutions and smart energy management for fleet upscale, based on the performed adaptations and modifications of the vehicles. To do so, vehicles, energy management solutions, charging interoperability tests, charging protocol improvements, charging strategies, and operational tools were developed and tested in real operation in a selection of demo cities. 
Adopting the opportunity charging solution along the line routes could minimize the number of required EBs and onboard battery capacity. Therefore, the operational and capital costs are decreased. With high charging power capability, the EBs could be operated without impact on their schedules and the EB fleet size could be minimized. In this work, the opportunity charging technologies with a power capability of $300-600 \mathrm{~kW}$ along the EBs' line route were developed. This aims to make EBs more affordable to help the public bus operators to adopt the EBs instead of the diesel buses. These opportunity charging solutions could optimize the EBs' operation in the following ways:

- $\quad$ Reduce the EBs fleet size.

- $\quad$ Reduce the onboard battery capacity needed, which would

Minimize the TCO,

Minimize the operational cost,

Increase the EBs' mileage due to decrease in onboard battery weight.

In this work, the developed EBs and E-truck are equipped with regenerative systems to optimize their operation and support their mileage. Such regenerative braking systems could recover a $65 \%$ of the maximum amount of recoverable energy [8]. Furthermore, the optimization of the E-truck consumption was implemented by replacing the electrical heating system with a HVAC system and by using the Compressed Natural Gas (CNG) Range Extender (REx) in the E-truck UC, which addresses aspects like energy efficiency, noise emissions, and pollution emissions.

This paper is organized as follows, Section 2 presents the demos in Barcelona, Osnabrück, and Munich. The characterizations and specifications of the EBs, chargers, and route lines were presented in detail. Furthermore, Section 2 deals with the collected measurements from the demo vehicles and the adopted methods of analyzing them. Section 3 includes the results and discussion of the collected measurements from demo vehicles and compares them with the measurements obtained by pieces of literature. Section 4 presents the conclusion of the whole work.

\section{Materials and Methods}

Two pantograph superfast-charging technologies based on an Automated Connection Device (ACD) were tested in this work, i.e., Type A and Type B. In Type A, the ACD is mounted within the charging station, typically on a pylon or within a building infrastructure. When a vehicle reaches the charging position, the pantograph connects to the vehicle. The setup requires wireless communication between the vehicle and the charger, as the pantograph down request needs to be transmitted from the vehicle to the charger before there is contact available between the systems.

In a roof-mounted ACD system, a pantograph is placed on top of the bus. This simplifies the charging stations, as the connector on the infrastructure side is static. Since the ACD is mounted on the vehicle, the cost of a charging station is lower, but the pantograph will add some weight, height, complexity, and cost to the vehicle.

The demonstrations of several HD-EVs (buses and trucks) were carried out, including their connections to the next generation of charging infrastructure in the selected city demonstrations (Barcelona, Osnabruck, Gothenburg, Eindhoven, and Jaworzno). In this work, three demos are presented, two for EBs, and one for an E-truck. The two EB demos took place in BARCELONA and OSNABRÜCK with EBs (Type A \& Type B) from four brands, i.e., Irizar, VDL, Heuliez, and Volvo, see Table 2.

Based on the operational specifications, requirements, and city need, as defined in ASSURED and the charge solutions, the UCs are implemented and operated in the project. An overview of the demos UCs is presented in this section. 
Table 2. Demo's overview.

\begin{tabular}{|c|c|c|}
\hline & BARCELONA & OSNABRÜCK \\
\hline Technology & ACD Type B & ACD Type A \\
\hline Vehicles & $\begin{array}{l}\text { - } \quad \text { VDL Citea SLF-120 Elec- } \\
\text { tric }(12 \mathrm{~m}) \\
\text { - } \\
\text { IRIZAR i2e }(18 \mathrm{~m})\end{array}$ & $\begin{array}{ll}\text { - } & \text { VDL Citea SLE-129 Electric }(12 \mathrm{~m}) \\
\text { - } & \text { HBA Heuliez GX437E }(18 \mathrm{~m}) \\
\text { - } & \text { IRIZAR i2e }(18 \mathrm{~m}) \\
\text { - } & \text { Volvo Gen2 City Bus }(12 \mathrm{~m}) \text { * }\end{array}$ \\
\hline Chargers & $\begin{array}{c}\text { ABB B \& Hex B @ depot } \\
\text { JEM B }\end{array}$ & $\begin{array}{c}\text { ABB A @ depot } \\
\text { Hex A }\end{array}$ \\
\hline
\end{tabular}

\subsection{Chargers}

The Electric Vehicle Supply Equipment (EVSE) is an essential part of the charging infrastructure, which could optimize the whole EB fleet operation and TCO of the entire system. There are two types of charger infrastructures, i.e., CSS2 in depot (40-150 kW) and opportunity charging on route lines, bus stops, or at terminals. The opportunity charging systems usually have various rated power levels: $150 \mathrm{~kW}, 300 \mathrm{~kW}, 450 \mathrm{~kW}$ up to $600 \mathrm{~kW}$ with the main feature being that charging can take place during the service along the EB route line [11].

As mentioned earlier, the HD-EVs have an average operation of around 16-20 $\mathrm{h}$ per day, which means the parking time of the HD-EVs is too short. Accordingly, fast-charging solutions are needed to meet the HD-EVs' demands without impacting their operation. In this work, as well the 10 chargers already installed on the three demo routes in Barcelona, there are three additional Type B chargers (roof-mounted pantograph) involved in the demonstration which are supplied by the ASSURED partners' ABB, Heliox (Hex), and Jema, Table 2.

The ABB and the Heliox chargers were installed in the triangle depot. The maximum power of both chargers was limited to $150 \mathrm{~kW}$ due to the limitations of the infrastructure at the depot. The Jema charger is in the terminal stop Carrer del Cisel, on the H16 Line. In [12], it was proven that the installation of the fast-charging solutions at the terminal, where buses are parked for a relatively long time, or on-street bus stops that are shared by many bus lines, results in an effective reduction of the size and total cost of the bus system's on-board batteries.

The ABB mobile HVC-PU (Type B) charger $300 \& 450 \mathrm{~kW}$ is a functional demo charger, especially designed for local events and tests.

The Heliox charger provided a mobile $300 \mathrm{~kW}$ charger with a contact hood (ACD Type B). The container has an ultra-fast battery charger system for EVs, and it is used as a charging unit for opportunity (on route) charging at stops along the route, see Figure 1.

The Jema ECI600 outdoor charger tested in Barcelona is designed to provide $600 \mathrm{~kW}$ of uninterrupted output if required. Due to the high power required at the opportunity charging stations, the chargers are usually installed directly at medium voltage (MV) along with all the necessary safety and protection elements required by the particular regulations of each country. However, in the Barcelona demos, the MV to LV installation had been carried out and more chargers were connected to the same LV network; an $\mathrm{LV} / \mathrm{LV}$ transformer had to be added to provide galvanic isolation to the Jema charger. Power requirements for the charger are $630 \mathrm{kVA}$; Electric grounding; IT power; Auxiliary TNS. The power can be supplied from the installation itself or, as in this case, using the $\mathrm{LV} / \mathrm{LV}$ transformer. 


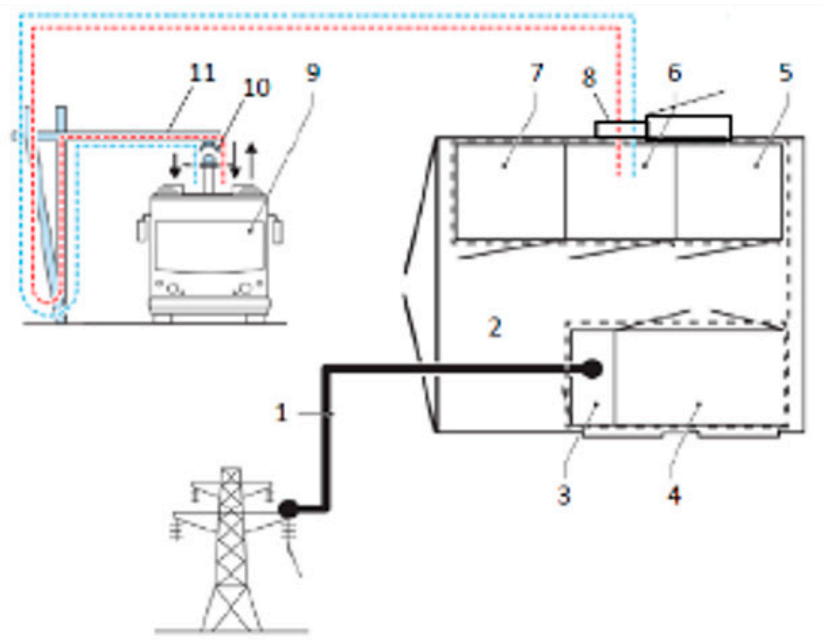

Figure 1. Heliox charger system overview. 1: AC grid connection, 2: Container, 3: AC income cabinet, 4: Transformer cabinet, 5: power converter cabinet, 6: Control cabinet, 7: AHU cabinet, 8: Status light and E-stop, 9: EB, 10: Contact hood, 11: Charging portal.

During installation, for the correct airflow necessary for the operation of the charger and the possible maintenance of the equipment, it is necessary that a distance of $800 \mathrm{~mm}$ is left free around the equipment.

In Barcelona, on bus service Line H16, there are two chargers located at each end of the line (terminals): Plaça Europa and Barcelona Port. Next to this in the Barcelona/TMB depot, there are 22 chargers located. The characteristics of those chargers are found in Table 3. Jema has completed the construction and commissioning of the last depot charging stations and designed the load control algorithm to minimize the use of network power during the peak load.

Table 3. Specifications of chargers in Barcelona and Osnabrück demos.

\begin{tabular}{|c|c|c|c|c|c|c|}
\hline \multirow{2}{*}{ Characteristics } & \multicolumn{2}{|c|}{ Opportunity Charging (on Route) } & \multicolumn{4}{|c|}{ Overnight Charging } \\
\hline & Barcelona & Osnabrück & \multicolumn{2}{|c|}{ Barcelona } & \multicolumn{2}{|c|}{ Osnabrück } \\
\hline Charging Technology & ACD Type B & ACD Type A & \multicolumn{2}{|c|}{ ACD Type B } & \multicolumn{2}{|c|}{ ACD Type A } \\
\hline Charging place & Terminal & On route & & Depot & & \\
\hline \multirow[t]{2}{*}{ Average charging time } & \multirow[t]{2}{*}{$4 \mathrm{~min}$} & \multirow[t]{2}{*}{$10 \mathrm{~min}$} & CCS2 & ACD Type B & CCS2 & $\begin{array}{c}\text { ACD } \\
\text { Type A }\end{array}$ \\
\hline & & & $6 \mathrm{~h}$ & $1.5 \mathrm{~h}$ & $5 \mathrm{~h}$ & $10 \mathrm{~min}$ \\
\hline No. of chargers & $4(2 \times 2)$ & 1 & 22 & 2 & 1 & 1 \\
\hline \multirow[t]{2}{*}{ Power $(\mathrm{kW})$} & \multirow[t]{2}{*}{600} & \multirow[t]{2}{*}{$300-450$} & CCS2 & $\begin{array}{c}\text { ACD } \\
\text { Type B }\end{array}$ & CCS2 & $\begin{array}{c}\text { ACD } \\
\text { Type A }\end{array}$ \\
\hline & & & 80 & 150 & 50 & 350 \\
\hline Daily charging efficiency & $95 \%$ estimating & $\begin{array}{c}95 \% \text { (in } \\
\text { data sheet) }\end{array}$ & $\begin{array}{l}95 \% \text { fo } \\
\text { (exclud }\end{array}$ & $\begin{array}{l}\text { charging } \\
\text { balancing) }\end{array}$ & & \\
\hline
\end{tabular}

In Osnabrück, on the route Line 15, there are two Type A opportunity chargers installed, one ABB Mobile HVC-PD 450 EB charger $(450 \mathrm{~kW})$ on the depot and one Heliox opportunity charger $(300 \mathrm{~kW})$ on the terminal station, Dodesheide Waldfriedhof. The characteristics of those chargers are found in Table 3. 


\subsection{Objectives}

Some data were collected from the chargers to investigate the following:

- Charger efficiency.

- Interoperability between chargers and EBs.

- Time for opportunity charging.

- Time needed for charging (compared with conventional): calculate the average waiting time of the EBs on the stations (e.g., from the velocity over the time) with and without charging. This time can possibly be used as opportunity charging time.

\subsection{EBs}

This section describes the EBs' UCs used in the Barcelona and Osnabrück demos. This demo is led by TMB, which is the largest public transport operator in Catalonia (Spain). The objective of the Barcelona demo is to demonstrate the interoperability of the bus chargers with Type B technology (roof-mounted pantograph). In the Barcelona demo, the full interoperability between EBs and chargers from various manufactures in real operating conditions was also demonstrated.

The demo in Osnabrück (Germany) aims to demonstrate the interoperability of EBs against ACD Type A technology (charger-mounted pantograph). Therefore, the full interoperability between EBs and chargers from various manufactures in real operating conditions is demonstrated. This demo is led by "Stadtwerke Osnabrück" SWO. The SWO is the local provider of public transport in Osnabrück. The following EBs are presented:

\subsubsection{Irizar ie Tram $(18 \mathrm{~m})$}

In the ASSURED project, an Irizar baseline electrical bus was converted to support an ACD Type B (roof-mounted technology) pantograph system to be used for superfastcharging $(500 \mathrm{~kW})$ and depot overnight charging (balancing mode). The replacement high(er)-power (C-rate) battery supports a maximum charging power of $500 \mathrm{~kW}$ but has less battery capacity than its predecessor $(150 \mathrm{kWh}$ instead of $340 \mathrm{kWh})$. Furthermore, the power consumption of the auxiliary equipment was optimized to include the HVAC and battery thermal management system (BTMS) in order to minimize the operation cost including the number of the frequency vehicles in the line route. Two Irizars' EBs were demonstrated, one in Barcelona with the Type B charging solution, and the other in Osnabrück with the Type A charging solution. The EBs are shown in Figure 2 and the vehicle specifications are found in [13].

\subsubsection{VDL Citea Buses}

The baseline VDL vehicle is a full electric city bus, the VDL Citea SLE(A) Electric, specifically developed for superfast-charging based on charging concepts Type A and Type B. The main objective for VDL was to upgrade the existing fast-charge technology and to demonstrate this technology on two VDL Bus \& Coach Citea electric buses, of which one is equipped with a Type A superfast $\mathrm{ACD}$ and the other is equipped with a Type $\mathrm{B}$ superfast ACD pantograph system. For this purpose, both VDL EBs were fitted with the latest charging strategies and with protocol implementations in accordance with the latest available standards.

Two different EBs from the VDL brand were tested in two different demo cities. The buses have similar technical specifications but one has an ACD Type B charging solution and the other has a Type A charging solution, see Figure $2 b$ and the specification in [14]. The drivelines and battery packs of both buses are the same, only the dimensions and the interiors differ between the two vehicles. These buses are VDL Citea, one tested in Barcelona, i.e., VDL Citea SLF-120 Electric $12 \mathrm{~m}$, and the other one in Osnabrück i.e., VDL Citea SLE-129 Electric $12 \mathrm{~m}$. 


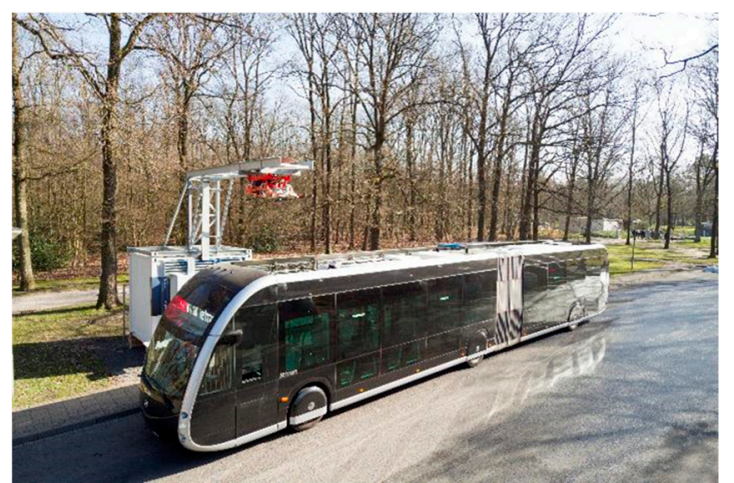

(a)

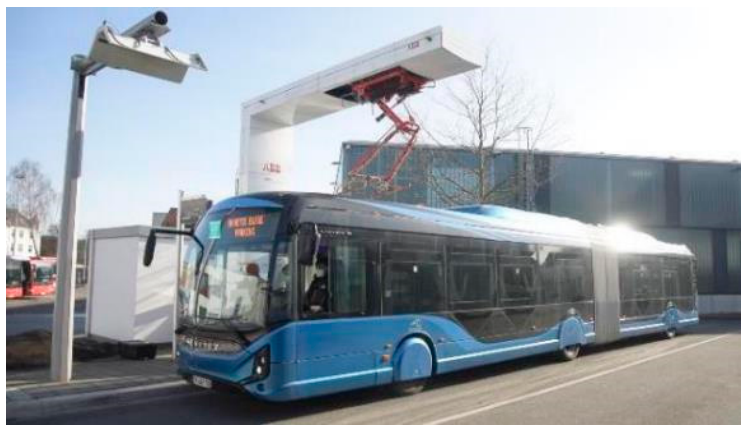

(c)

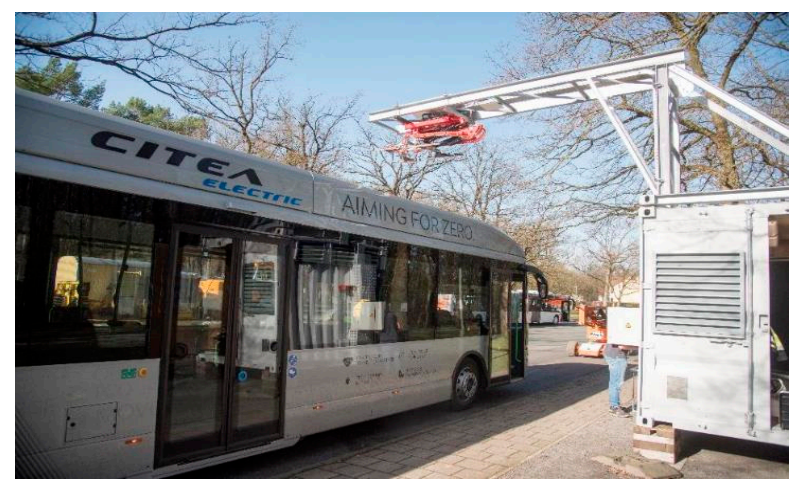

(b)

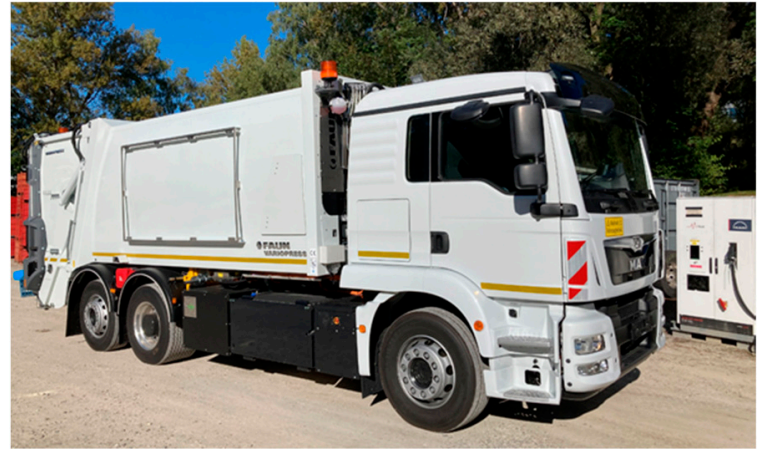

(d)

Figure 2. IRIZAR ieTram $18 \mathrm{~m}$ articulated EB [13] (a) IRIZAR ieTram $18 \mathrm{~m}$ articulated EB in Osnabrück at Waldfriedhof charging station, Type A, (b) VDL Citea SLE-129 at Waldfriedhof charging station, Type A, (c) Heuliez GX437E 18 m bus at SWO depot [14], (d) MAN refuse collection E-truck.

\subsubsection{Heuliez GX437 (18 m)}

The baseline Heuliez vehicle is an $18 \mathrm{~m}$ articulated urban electric Bus (Heuliez Bus GX437E), see Figure 2c and vehicle specifications in [15]. For urban transportation operations, mainly with articulated EBs, overnight charge requires unacceptable ESS sizing (a huge amount of $\mathrm{kWh}$ batteries are required to be embedded). The baseline bus was equipped with a high-power optimized battery with acceptable energy capacity and sizing and an ACD pantograph Type A system with a power of up to $450 \mathrm{~kW}$ acceptance power capability.

Starting from the vehicle baseline, the HB GX437E $18 \mathrm{~m}$ bus was adapted to achieve the following performance objectives:

- A BEV $18 \mathrm{~m}$ articulated urban electric bus with superfast-charging capability with ACD Type A technology developed for urban transportation (model GX437E with opportunity superfast-charging capability).

- $20 \mathrm{~h} \mathrm{~EB}$, range $300 \mathrm{~km}$ with superfast charge $>400 \mathrm{~kW}$ at bus terminal or last stop.

- Up to $30 \mathrm{~km}$ electric range from $100 \% \mathrm{SoC}$.

- ACD Type A technology with a max power greater than $400 \mathrm{~kW}$.

- CCS Combo 2 (mode 4) for depot charging.

- Only ZEV operation.

- Charging time $<5 \mathrm{~min}$ (for $12 \mathrm{~km}$ superfast charging).

- TCO similar to diesel bus by considering environmental cost, according to green public procurement directive, exemptions, and institutional support.

- Minimized impact on the power grid.

- Standardized superfast-charging to guarantee interoperability.

- Demonstration in real operation. 


\subsubsection{Line Operations}

The Barcelona demo embraces three routes for demonstrating the interoperability within the ASSURED project. The routes are shown in Figure 3.

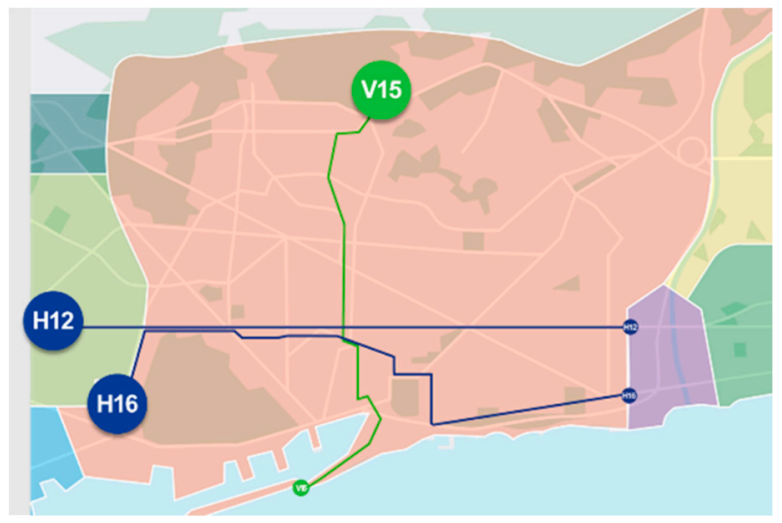

Figure 3. Overview of the ASSURED demo lines in Barcelona.

In this work, the data from the EBs were analyzed in the working route over Line H16. Therefore, only the characteristics of this line route are listed in Table 4.

Table 4. Characteristics of route Line's demos in Barcelona and Osnabrück.

\begin{tabular}{|c|c|c|}
\hline & H16 in Barcelona & Line 15 in Osnabrück \\
\hline Typology of the Line & Centre & Centre \\
\hline Topography of the route Line & Flat & Flat \\
\hline $\begin{array}{l}\text { Average commercial speed } \\
(\mathrm{km} / \mathrm{h})\end{array}$ & 12 & 12 \\
\hline SORT Type & 1 & 1 \\
\hline Line length $(\mathrm{km})$ & 12 & 4 \\
\hline $\begin{array}{l}\text { Total no. of stops along the } \\
\text { route line }\end{array}$ & 35 & 12 \\
\hline $\begin{array}{l}\text { Average distance between } \\
\text { stops }(\mathrm{m})\end{array}$ & 350 & 350 \\
\hline $\begin{array}{l}\text { Total daily hours of } \\
\text { operation (h) }\end{array}$ & 16 & 16 (COVID period) \\
\hline $\begin{array}{l}\text { Total daily hours of operation } \\
\text { in full electric }(\mathrm{h})\end{array}$ & 16 & 16 \\
\hline $\begin{array}{l}\text { Total km driven/vehicle/day } \\
\qquad(\mathrm{km})\end{array}$ & 190 & 100 \\
\hline $\begin{array}{l}\text { Total power consumption } \\
(\mathrm{kWh})\end{array}$ & 380 (winter) & N.A. \\
\hline $\begin{array}{l}\text { Total no. of buses on the line } \\
\text { including non-electric }\end{array}$ & 19 & $4 \mathrm{ASR}+5$ SWO fleet \\
\hline $\begin{array}{l}\text { Total no. of passangers } \\
\text { expected on the line in } \\
\text { average (day) }\end{array}$ & $\begin{array}{l}17,900 \text { (normal condition, } \\
\text { summer) }\end{array}$ & 2400 \\
\hline
\end{tabular}

In the Osnabrück demo, during the demo period, four EBs from various brands were operated on Line 15, which starts at the SWO depot in Osnabrück and goes from the main train station to station Dodesheide Waldfriedhof. The characteristics of Line 15 are listed in Table 4. 
During the demo period in Osnabrück, there was an issue with the CAN connection of the built-in data logger of the Heuliez EB; therefore, no data from the bus were obtained. As a replacement, Heuliez provides data from the city of Trondheim in Norway, see Figure 4, with the same vehicle configuration as the demo bus in Osnabrück. The total mileage of the vehicle is $115.850 \mathrm{~km}$.

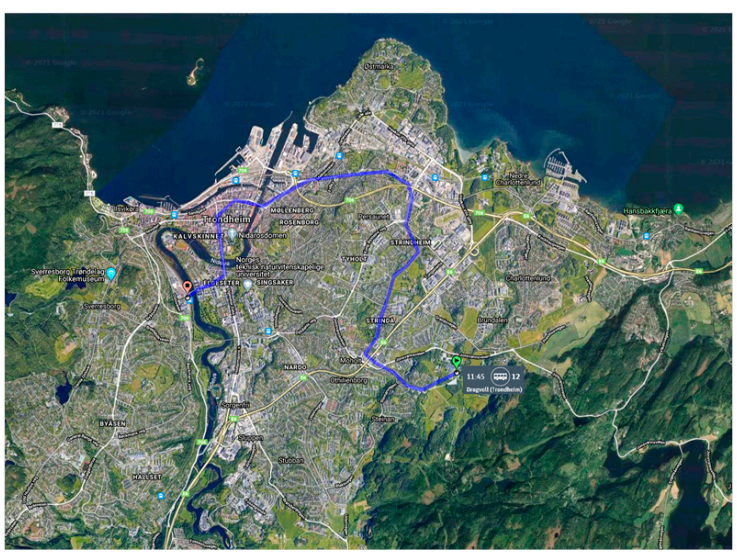

Figure 4. Line 12 Trondheim (Norway).

Several parameters were recorded with different intervals of event trigger during the measurement including Vehicle mileage; GPS Longitude and Latitude $\left(^{\circ}\right)$; Door status; SoC; Total charging time; and Vehicle energy consumption.

\subsubsection{Objectives}

Most of the EBs and some of the chargers are equipped with a CAN-bus logger to collect the operational data from the EBs demos i.e., Irizar, VDL, and Heliox. The collected data were used to measure and improve the energy consumption of the battery thermal management system (BTMS). Similarly, the use of energy for auxiliary loads has been measured and optimized. The following analyses were implemented:

- Energy consumption.

- $\quad$ Electric driving range and Electric driving time (without the need for charging).

- $\quad$ Mileage.

- $\mathrm{CO}_{2}$ emission.

The determination of the above KPIs gives important additional information from the real-world application to address some research questions from the stakeholders. In [16], a test method was developed to select a bus in such a way to lower the operational cost and TCO and provide a better service. The included KPIs are power consumption, charging duration, driving distance, and failure duration. In this work, the following KPIs were adopted to study the EBs behavior.

\subsection{E-Truck Demo (Munich, Germany)}

\subsubsection{Baseline Truck}

The baseline vehicle is a MAN, Battery Electric Vehicle (BEV) Truck, BEV-Truck (TGM 6x2/4), with a drivetrain configuration suitable for distribution purposes. A photo of the vehicle is shown in Figure $2 d$, and Table 5 lists the specifications of the E-truck. Several improvements in the truck configuration have to be done to make it fit for refuse collection application, for example, using HVAC instead of electrical heater, installing the packages of the batteries in the truck body, integrating the Range Extender (REx) module and tank system on the truck frame as well as setting up the smart energy management. 
Table 5. MAN refuse collection truck specifications.

\begin{tabular}{cc}
\hline Specifications & Values \\
\hline Fuel & Electricity and CNG (TGM 6x2/4 model) \\
\hline Weight & Max. vehicle weight $27,000 \mathrm{~kg}$ \\
\hline Passenger capacity & $2(3)$ \\
\hline Drivetrain size & Electric- $250 \mathrm{~kW}$ peak, $120 \mathrm{~kW}$ cont. \\
\hline Battery capacity & $148 \mathrm{kWh}, \sim 110 \mathrm{kWh}$ usable \\
\hline Range & $50-120 \mathrm{~km}$ in BEV mode depending on topology, etc. \\
\hline Range extender size & $1,41 \mathrm{CNG}$ engine with electric output $\sim 50 \mathrm{~kW}$ cont. \\
\hline Range extender capacity & $22 \mathrm{~kg}$ CNG ( 100 kWh electric) \\
\hline Link to the baseline vehicle & https://www.truck.man.eu/de/en/trucks/tgm/ \\
tgm.html; accessed on 9 January 2022
\end{tabular}

\subsubsection{E-Truck}

The main objective of this demo in Munich (Germany) is to demonstrate an E-truck for refuse collection operations with a drivetrain and its auxiliary units optimized with regard to energy consumption. Pursuing this goal, one REx module running on CNG was developed, integrated, and demonstrated in a dedicated timespan during this UC. The module is able to fast charge during transport operation mainly outside of downtown areas and has the potential for installation and use in commercial BEV-Trucks. The aim is to reduce the TCO and achieve a higher payload, which leads to a maximized competitiveness against conventional low emission trucks. The E-truck is equipped with a CCS2 connector with $150 \mathrm{~kW}$ of power. The objective of this demo is summarised as follows:

- $\quad$ Realization Battery Electric Vehicle (BEV-Truck) ((medium-duty) TGM 6x2/4) with highly efficient drivetrain developed for refuse collection purposes.

- Zero emissions during refuse collection operation in inner-city areas (BEV-Mode).

- Low emissions during transport of garbage to recycling ground in suburban areas (REx-Mode aiming at Euro VI with a conformity factor of 1.2 (availability of EURO IV engines in suitable power range provided)).

- $\quad$ Fully integrated and optimized energy and recuperation management.

- Pure electrical driving range of at least $50 \mathrm{~km}$.

- Low noise during operation $(<72 \mathrm{~dB})$.

- $\quad$ Energy-efficient auxiliary units for maximized driving range (e.g., HVAC).

- TRL 6-7 achieved after successful demonstration of the truck in operational environments.

One further task is to deal with the optimization of the auxiliary units' energy efficiency. The components in focus are the cooling system, cabin heater, and air conditioning, the aim is to minimize the energy consumption and maximize the driving range according to the requirements of electrical drivetrains. The efficiency of the cabin heating and the driving range will be simultaneously increased by using new HVAC technologies like heat pumps that use R744 (carbon dioxide) as refrigeration fluid. An optimized HMI interface will contribute to anticipatory driving leading to the reduced energy consumption of the E-Truck.

The E-truck is equipped with a data logger which records all relevant CAN-communication and uploads the needed signals to cloud storage via LTE once a day. With this, actual data from the vehicle can be accessed every day.

The recorded signals, such as voltages, currents, temperatures, and operating modes of all-electric components (batteries, axle, charging interface, auxiliary units, compressor, heater, etc.), driving information from the base vehicle and an additional GPS receiver and control signals of the three rapid prototyping ECUs (e.g., Micro-auto-box) are responsible for controlling the vehicle and the optimized energy management. The cooling and refrigerant 
circuits are equipped with several temperature, pressure, and flowrate-sensors which are connected via A-/D-converters to the data logger.

To evaluate the outcome of this demo, some measurements data were considered. These data are used to evaluate the following outcomes of this demo:

- Combustion engine on/off: The use of the range extender has to be logged in order to give information about the frequency and place of its use.

- GPS gives information of the mileage, velocity, high profile, and the location where the range extender is running during operation and is, therefore, valuable.

- Energy consumption is important for the operation and operational costs.

- $\mathrm{CO}_{2}$ and pollutant emission of the range extender unit and of a diesel baseline for comparison must be measured.

- Mileage is also an important asset to refer to aspects like emissions and energy consumption.

\section{Results and Discussion}

This section presents the data analyses for the EBs and E-Truck for the evaluation of the operational performance and how it was impacted according to the adopted optimization techniques.

\subsection{EB Demos}

The EB demos were held in Barcelona and Osnabrück. The EBs were selected from four various brands, i.e., Irizar, VDL, Heuliez, and Volvo. The Volvo EB is not presented in this work as the objective of the test is beyond the scope of this study for this EB. In this work, fast-charging solutions based on pantograph Type A \& Type B were tested in the bus operator depot and on the line route. The pantograph charging solutions were selected from three various brands, i.e., Jema, ABB, and Hex, to test the interoperability between the EBs and the chargers.

\subsection{Irizar $E B$}

Measurements were collected from Irizar buses while driving in Barcelona on route Line H16. In the Osnabrück demo, one hour and eleven minutes (01h:11min) of Irizar data were collected. These data were recorded on the 30th of April 2021 at 9:39. These data were recorded while the Irizar bus was driving on the line route 15 in Osnabrück. 3.2.1 Interoperability.

The Irizar EBs were already driving in Barcelona as part of the TMB bus fleet, therefore, no major interoperability issues were to be expected with the already installed charging infrastructure. From the already installed fast chargers in Barcelona, the charger's data were obtained from mid-December 2020 until the beginning of February 2021, which showed that the majority of the charging sessions (94\%) reached the targeted SoC of $90 \%$ without any interoperability issue. From the $6 \%$ of the sessions that did not reach the targeted SoC, it was observed that $66 \%$ originated from an uncontrolled stop. The most likely reason for this is that the bus driver initiated a stop of the charging session by lowering the pantograph before reaching the targeted end SoC. In the other cases ( $2 \%$ of the total), the reason remains unclear. There are, in the aforementioned timeframe, no charging sessions observed in which no energy was charged. Only $1 \%$ of the charging sessions corresponded with $2 \mathrm{kWh}$ of charged energy or less. The lowest observed energy transfer was $0.7 \mathrm{kWh}$.

\subsubsection{Charging Rate}

The power transfer rate from the chargers to the EBs was analysed to investigate the average and maximum transfer power from the chargers and the achieved SoC and their corresponding charging time. It was observed that most of the average charging rates were realized when the measured 668 charging sessions was $353 \mathrm{~kW}$. The average amount of charged energy was approximately $22 \mathrm{kWh}$, providing an average driving range of almost $14 \mathrm{~km}$ after charging. The maximum average charging power for a single charging session was $486 \mathrm{~kW}$ ( $3 \%$ lower than the theoretical maximum). The difference between the average 
power and the maximum charging power can be mostly explained by the fact that above $80 \%$ of SoC, the charging speed will be reduced by the battery management system (BMS). It has been observed that charging sessions with high power tend to be short sessions and that most charging sessions in Barcelona lasted $5 \mathrm{~min}$ and were charging at around $350 \mathrm{~kW}$. It is expected that if the initial SoC is low, then the average charging power will increase.

\subsubsection{Consumption}

From the Irizar bus in Osnabrück, one hour and eleven minutes of recorded data were analysed when the EB was under test (empty without passengers). From the obtained data, the following analyses parameters were derived, see Table 6 . For these measurements, no passengers were present in the bus.

Table 6. Aggregated data from the IRIZAR EB in Osnabrück.

\begin{tabular}{|c|c|c|c|c|c|}
\hline EB Battery Capacity & & 150 & \multicolumn{2}{|c|}{ Total Duration of the Measured Data (h) } & 01:11:26 \\
\hline \multicolumn{4}{|c|}{ Speed Measurements } & \multicolumn{2}{|c|}{ Energy Use Calculations } \\
\hline $\begin{array}{c}\text { Average speed 09:44: } 30 \text { to } \\
\text { 09:53:47 }(\mathrm{km} / \mathrm{h})\end{array}$ & 33.1 & $\begin{array}{c}\text { Max speed 09:44: } 30 \text { to } \\
\text { 09:53:47 }(\mathrm{km} / \mathrm{h})\end{array}$ & 61.3 & $\begin{array}{c}\text { Estimated energy } \\
\text { consumption 09:44: } 30 \text { to } \\
\text { 09:53:47 }(\mathrm{kWh} / \mathrm{km})\end{array}$ & 1.8 \\
\hline $\begin{array}{c}\text { Average speed 10:32: } 08 \text { to } \\
\text { 10:47:59 }(\mathrm{km} / \mathrm{h})\end{array}$ & 21,0 & $\begin{array}{c}\text { Max speed 10:32: } 08 \text { to } \\
\text { 10:47:59 }(\mathrm{km} / \mathrm{h})\end{array}$ & 67.5 & $\begin{array}{c}\text { Estimated energy } \\
\text { consumption 10:32: } 08 \text { to } \\
\text { 10:47:59 }(\mathrm{kWh} / \mathrm{km})\end{array}$ & 1.3 \\
\hline Total average speed $(\mathrm{km} / \mathrm{h})$ & 25.5 & Total max speed $(\mathrm{km} / \mathrm{h})$ & 67.5 & $\begin{array}{c}\text { Estimated energy } \\
\text { consumption overall } \\
(\mathrm{kWh} / \mathrm{km})\end{array}$ & 1.6 \\
\hline \multicolumn{2}{|c|}{ Charging measurements } & \multicolumn{2}{|c|}{ Soc measurements } & $\begin{array}{c}\text { Estimated energy use } \\
\text { 09:44:30 to 09:53:47 (kWh) }\end{array}$ & 9 \\
\hline Charged energy (kWh) & 14.4 & $\begin{array}{l}\text { Delta SoC driving 09:44: } \\
\quad 30 \text { to } 09: 53: 47(\%)\end{array}$ & -6 & \multirow{3}{*}{$\begin{array}{c}\text { Estimated energy use } \\
\text { 10:32: } 08 \text { to 10:47:59 } \\
\text { (kWh) }\end{array}$} & \multirow{3}{*}{7.2} \\
\hline Charging time (min) & 3 & \multirow{2}{*}{$\begin{array}{l}\text { Delta soc driving } \\
\text { 10:32:08-10:47:59 }\end{array}$} & \multirow{2}{*}{-4.80} & & \\
\hline Delta SoC charging (\%) & 9.6 & & & & \\
\hline \multicolumn{2}{|c|}{ Distance measurements } & $\begin{array}{c}\text { Total distance } 09: 44: 30 \text { to } \\
09: 53: 47(\mathrm{~km})\end{array}$ & 5.02 & $\begin{array}{c}\text { Total distance 10:32: } 08 \text { to } \\
\text { 10:47:59 }(\mathrm{km})\end{array}$ & 5.42 \\
\hline
\end{tabular}

Aggregated measurements from Barcelona reveal that when the electricity consumed by the chargers covering a whole season is compared with the number of kilometres driven by the EB fleet, it results in an average energy consumption of $2.0 \mathrm{kWh} / \mathrm{km}$ in wintertime and up to $3.1 \mathrm{kWh} / \mathrm{km}$ during the summer season. This is considerably more than what was measured in Osnabrück. The delta comprises that no payload/passengers were present in Osnabrück, implying less or no air-conditioning (auxiliary) losses in Osnabrück. The aforementioned results are in line with the those reported in [6], where in the EB that use diesel heating, the consumption is around $1.5 \mathrm{kWh} / \mathrm{km}$. In this work, the power consumption of auxiliary pieces of equipment within the demo vehicles was optimized to include the HVAC in order to improve the performance of the vehicles. Compared with the data obtained from ViriCiti, a $12 \mathrm{~m}$ EB can have a mileage of $375 \mathrm{~km}$ with a battery capacity of $300 \mathrm{kWh}$; this mileage considerably declined to $120-130 \mathrm{~km}$ in winter when the EB was electrically heated, whereas with diesel heating, it could achieve $200 \mathrm{~km}$ of mileage range.

Most of the EBs are equipped with regenerative systems. A total of $5 \%$ of recuperated power is obtained when the drivers push the brake firmly, while a $35-40 \%$ of the recuperated power could be obtained if the drivers apply the brake more smoothly. It was found that the low temperatures $\left(-5^{\circ} \mathrm{C}, 0^{\circ} \mathrm{C}\right)$ have an impact of up to $38 \%$ on the vehicle range in cases of $\mathrm{BEB}$, and up to $23 \%$ for hydrogen-powered buses [7].

It is worth mentioning that in Barcelona, the same EBs with a diesel powertrain would be using 70-75 $\mathrm{L}$ of diesel per $100 \mathrm{~km}$ of range. The much smaller seasonal effect $(7 \%$ versus $76 \%$ difference) with diesel buses can be explained by: 
- All energy for heating and cooling needs to come from the battery, whereas:

- With diesel buses, (waste) heat is readily available;

- With the diesel buses in the TMB fleet, the HVAC system is already very optimized by using more energy while the EB is retarding (i.e., regenerating energy through its HVAC system) and while the diesel engine is under low loads and therefore inefficient (e.g., while idling).

These observations are very relevant when referring to the electric fleet (more specifically: the battery sizes, C-rate, chargers, and bus-line planning) and imply that for fleet operators that want to make the transition towards a (partial) zero emission fleet, it is of paramount importance to pre-investigate the vehicle's energy consumption under (possibly several) worst case conditions and to take these into account in the vehicle specifications and the schedule (time for charging). When doing this, it is generally worth considering taking the costs and benefits from energy saving measures into account.

The obtained results and conclusions are in line with those presented in [6], where three articulated EBs with a length of $18 \mathrm{~m}$ from three various brands (i.e., Bozankaya Sileo, and Solaris) were tested in three days of operation in Bonn (Germany). The measured consumption (heating off but air conditioning on) for the three EBs was between 1.65-1.84 kWh $/ \mathrm{km}$. According to these data, a range between 190 and $210 \mathrm{~km}$ can be covered by an $18 \mathrm{~m}$ EB with $350 \mathrm{kWh}$ of battery capacity. However, the energy consumption could be different for the same EBs with the same, length, capacity, load condition, etc. This could be explained due to the traffic conditions (or terrain) from one line to another or from one city to another. In urban areas, the EB spends much time stopping and moving at low speeds, it consumes energy even when it is stopped at the traffic jam because it must supply the auxiliaries. For example, in [8], this occurs in route Line 6, which is $7.9 \mathrm{~km}$ long and connects Porto Vado to "Via Alessandria" in Savona, Italy. The route lines are analyzed in two parts according to the ground characteristics. The first part of the route line $(700 \mathrm{~m})$ passes through the city center, starting from Via Paolo Boselli and finishing at its destination of "Via XX Settembre". The other and longer part of the route line $(1450 \mathrm{~m})$ heads to the west following the seafront of Savona, which goes from the bus stop Villa Zanelli to Via Nizza (Camping) until it reaches its destination, Via Nizza 126. In the first part, the estimated consumption is about $2.47 \mathrm{kWh} / \mathrm{km}$, while in the second part it is $2.62 \mathrm{kWh} / \mathrm{km}$.

\subsection{VDL EB}

The collected VDL data are from the time period of 10 November 2020 until 30 May 2021 (for Barcelona demo) and from the time period of 18 December 2020 until 1 June 2021 (for Osnabrück demo).

\subsubsection{Charger Efficiency}

From the Barcelona data set, it can be observed that the maximum charging rate achieved is around $340 \mathrm{~kW}$. The VDL bus was charged in Osnabrück with a maximum rate of $330 \mathrm{~kW}$.

In Barcelona, the VDL data were matched against the data of the ABB charger, so that a comparison could be made between the amount of energy delivered from the grid versus the amount of input energy received by the vehicle battery.

On 16 February 2021, a $69.85 \mathrm{kWh}$ transfer of energy was measured on the charger (AC side) and $68.90 \mathrm{kWh}$ was measured at the vehicle side, resulting in $98.64 \%$ charger efficiency during a 32 min charging session. On 19 February 2021, a $13.37 \mathrm{kWh}$ transfer of energy was measured on the charger (AC side) and $13.26 \mathrm{kWh}$ was measured at the vehicle side, resulting in $99.16 \%$ charger efficiency during a 10 min charging session. The conditions were quite similar: both charging sessions reached the same maximum power of $147 \mathrm{~kW}$ and both sessions were in the early morning (16th: 8:37-9:09 @ $13{ }^{\circ} \mathrm{C}$ vs. 19th: 7:01-7:11@ $10.5^{\circ} \mathrm{C}$ ). The difference in charger efficiency may be explained by the lower energy transfer and lower temperatures on the 19th, resulting in a lower cooling demand on the charger side. In general, it can be said that conditioning of the (power) 
electronics may contribute significantly (up to 10\%) to the overall power consumption due to the energy use of cooling equipment (fans) and cabinet conditioning (heating and cooling to ensure that all components of the charger remain within the specified temperature range).

\subsection{2. $\mathrm{CO}_{2}$ Saving}

The benefits gained from the TMB fleet electrification in Barcelona are seen with an emission reduction of $1.8 \mathrm{t} \mathrm{CO}_{2}, 540 \mathrm{~kg}$ of $\mathrm{NO}_{\mathrm{x}}$, and $6 \mathrm{~kg}$ of PMx by using only EBs instead of diesel buses. Furthermore, regarding the fuel cost, there is an expected reduction of $30 \%$ by 2024 for using electricity instead of diesel, which means a reduction of $1.5 \mathrm{M} €$ per year. Overall emissions and costs are reduced, combined with higher passenger comfort and less driving noise.

\subsection{Heuliez EB: Operational Parameters Analyses}

In this section, the operational parameters of the Heuliez EB were analyzed. The parameters include charging C-rate, charging time, and energy consumption. Furthermore, some other statistical analyses were implemented, including daily driving distance, daily operational time, number of fast charges, number of slow charges, etc. The analyses based on obtained data are from 15 June 2021 to 22 June 2021 of Line 12, which operated between St. Olavs Hospital/Øya to Sentrum Strindheim and Dragvoll (https://www. atb.no/trondheim-area/category2822.html, accessed on 1 Jan 2022), see Figure 4 . Line 12 includes 29 bus stops in total. The data include the total distance of the line route, i.e., 2.061 $\mathrm{km}$ during operation.

The external temperatures during the operation week vary from $6{ }^{\circ} \mathrm{C}$ to $22{ }^{\circ} \mathrm{C}$ with an average of $15^{\circ} \mathrm{C}$. Therefore, the temperatures are comparable with the autumn in Osnabrück. To get an impression of the daily routine of the bus, Figure 5 shows the GPS and the SoC throughout the day on the 15 June. The beginning and the end of the vehicle usage were at the depot. The vehicle starts with a fully charged battery. During the day, the vehicle drove between "St. Olavs Hospital/Øya" and "Dragvoll". At the stop at both ends, the vehicle was charged via opportunity charging for around 2-6 min. The opportunity charging time differs because charging was done in the time buffer to keep to the time schedule of the route line. The average SoC is on a high level of more than $70 \%$ so that in a case of a delay, the opportunity charging time can be shortened without the risk of low energy. At midday on 15 June, there was a break of around $1 \mathrm{~h}$ at the depot, where the vehicle was slowly charged.

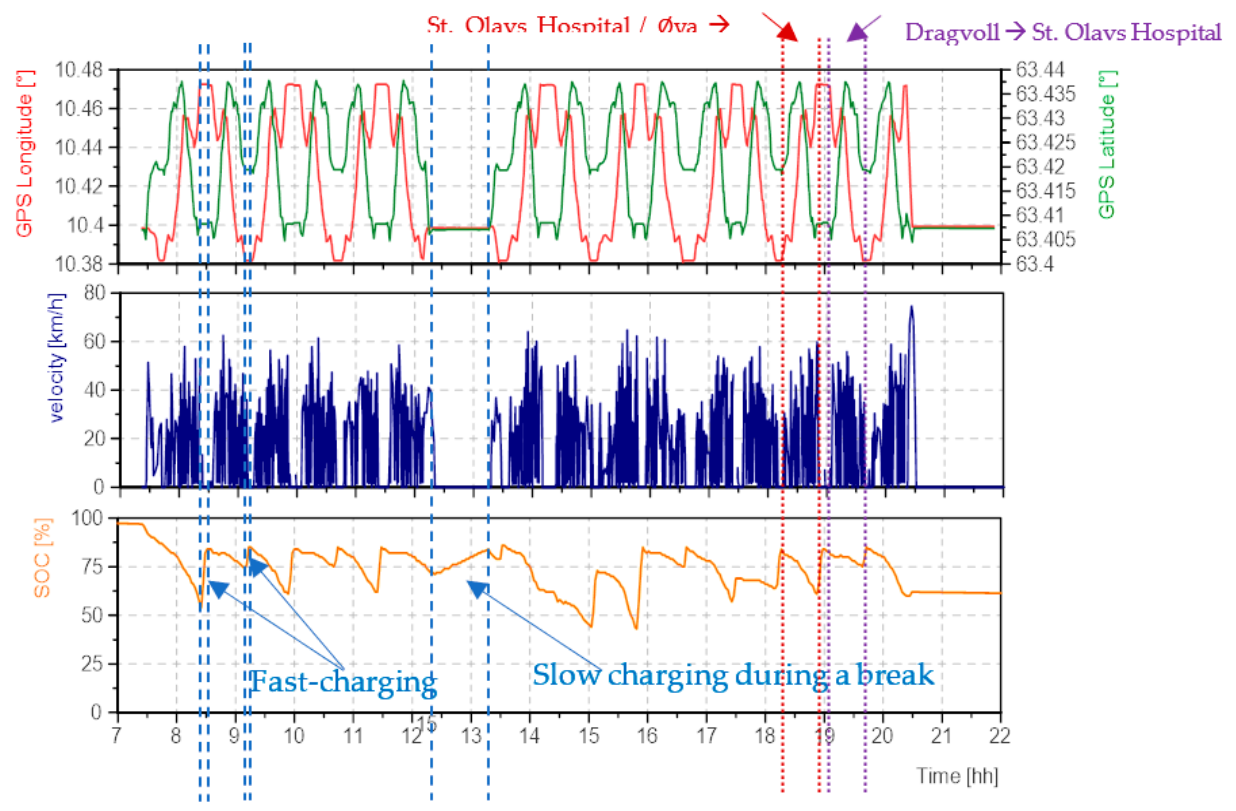

Figure 5. GPS, velocity and SoC from the Trondheim, 15 June 2021. 
Some of the operational parameters were analyzed statistically and presented in Table 7 , which lists the minimum, maximum, and average values of the operational EB parameters.

Table 7. Total operational parameters values Trondheim 15 June 2021 to 22 June 2021.

\begin{tabular}{|c|c|c|c|c|}
\hline Value & Average & Minimum & Maximum & Sum \\
\hline Daily operational time hh:mm] & $13: 14$ & 09:46 & 18:03 & $94: 44$ \\
\hline Daily number of trips, Line 12 & 15.7 & 13 & 22 & 110 \\
\hline Daily driving distance $[\mathrm{km}]$ & 294.5 & 219.2 & 410.3 & 2061.3 \\
\hline Daily average velocity $[\mathrm{km} / \mathrm{h}]$ & 22.2 & 20.7 & 22.9 & N.A. \\
\hline Inside temperature $\left[{ }^{\circ} \mathrm{C}\right]$ & 20.6 & 9 & 27 & N.A. \\
\hline Outside temperature $\left[{ }^{\circ} \mathrm{C}\right]$ & 15.2 & 6 & 22 & N.A. \\
\hline Daily number of fast charges & 12.7 & 9 & 21 & 89 \\
\hline Daily number of slow charges & 1.4 & 1 & 2 & 10 \\
\hline $\begin{array}{l}\text { Daily charging time (fast charging) } \\
\text { [minutes] }\end{array}$ & 57.1 & 38 & 94 & 400 \\
\hline $\begin{array}{l}\text { Daily charging time (slow charging) } \\
\text { [minutes] }\end{array}$ & 183.6 & 24 & 336 & 1285 \\
\hline SoC [\%] & 76.2 & 25 & 99 & N.A. \\
\hline Total delta SoC (fast charging) [\%] & 247.7 & 163 & 337 & 1134 \\
\hline Total delta SoC (slow charging) [\%] & 37.1 & 3 & 62 & 260 \\
\hline $\begin{array}{l}\text { Proportion of charging time (fast } \\
\text { charging) to operational time [ } \%]\end{array}$ & Nonvalue & 6.5 & 8.7 & 7.2 \\
\hline C-rate (fast charging) & 2.6 & 1.1 & 4.8 & N.A. \\
\hline C-rate (slow charging) & 0.13 & 0.08 & 0.17 & N.A. \\
\hline Energy consumption $[\mathrm{kWh} / \mathrm{km}]$ & 1.38 & 1.28 & 1.52 & N.A. \\
\hline
\end{tabular}

As can be seen from the table above, some observations regarding operational parameters could be summarized:

- $\quad$ The C-rate of every single charge was calculated.

- The average C-rate of the opportunity charging is around 20 times higher than the slow charging during nights and stops.

- During operation, only around $7.2 \%$ of the operational time is used for charging (without overnight charging). This small amount of required charging time can be provided by the typically scheduled waiting times in the stops at the end of the line. These waiting times are also scheduled for diesel baseline busses as a time buffer, for a short break of the driver, and for driver changes. Thus, in this case, there is no extra time needed for EB charging.

- The average energy consumption is $1.4 \mathrm{kWh} / \mathrm{km}$. It is important to mention that this value is estimated from the output power of the battery and does not include the energy losses from the charger, the charging progress, and the battery.

- Average daily operational time is $13 \mathrm{~h}$ and $14 \mathrm{~min}$ and the driving distance is $294.5 \mathrm{~km}$. With opportunity charging on Line 12, the EB can operate like the baseline diesel bus.

- The average charging time (fast charging) is $5 \mathrm{~min}$ with an average delta SoC of $19.6 \%$. With a battery capacity of $102 \mathrm{kWh}$, the average charging amount is $20.0 \mathrm{kWh}$.

- The fast chargers need $261 \mathrm{~kW}$ on average and a maximum of $490 \mathrm{~kW}$ as a power requirement (plus the energy losses from the charger, the power transfer, and battery charging). 
The obtained results are comparable with some obtained in the literature. In [16], some EBs from four brands were tested, i.e., BYD, Skywell, Yinlong, and Jiankang. The EBs include buses with a length of $8 \mathrm{~m}$ and $10 \mathrm{~m}$. The EBs of $10 \mathrm{~m}$ in length showed higher power consumption than the $8 \mathrm{~m}$ buses. For example, per $100 \mathrm{~km}$, some $10 \mathrm{~m}$ EBs consumed $100 \mathrm{kWh}, 93 \mathrm{kWh}, 106 \mathrm{kWh}$, and $102 \mathrm{kWh}$, for $8 \mathrm{~m}$ EBs, the consumptions were $83 \mathrm{kWh}, 73 \mathrm{kWh}, 94 \mathrm{kWh}$, and $80 \mathrm{kWh}$. While the charging duration was almost equal, for example, for $10 \mathrm{~m}$ EBs it was $28 \mathrm{~min}, 16 \mathrm{~min}, 27 \mathrm{~min}$, and $23 \mathrm{~min}$, and for $8 \mathrm{~m}$ EBs it was $29 \mathrm{~min}, 16 \mathrm{~min}, 28 \mathrm{~min}$, and $20 \mathrm{~m}$. The daily average driving distances of most EBs are equal and around $200 \mathrm{~km}$.

In October 2019, a new record was marked by the EB from Iveco with the Iveco E-WAY $12 \mathrm{~m}$ (Heuliez GX 337 Elec), where on a single charge the bus covered as many as $527 \mathrm{~km}$ during a test day. The bus travelled with an average speed of $46 \mathrm{~km} / \mathrm{h}$ for $12 \mathrm{~h}$. The heating and air conditioning were turned off. This remarkable driving range couldn't be achieved in normal traffic conditions [6].

\subsection{E-Truck}

While REx was being build and put into operation in the MAN E-Truck, the tests and measurements were done. Graphs of the engine torque and speed, Compressed Natural Gas (CNG) mass flow, and produced electric power of the REx module running on a test bench are shown in Figure 6.
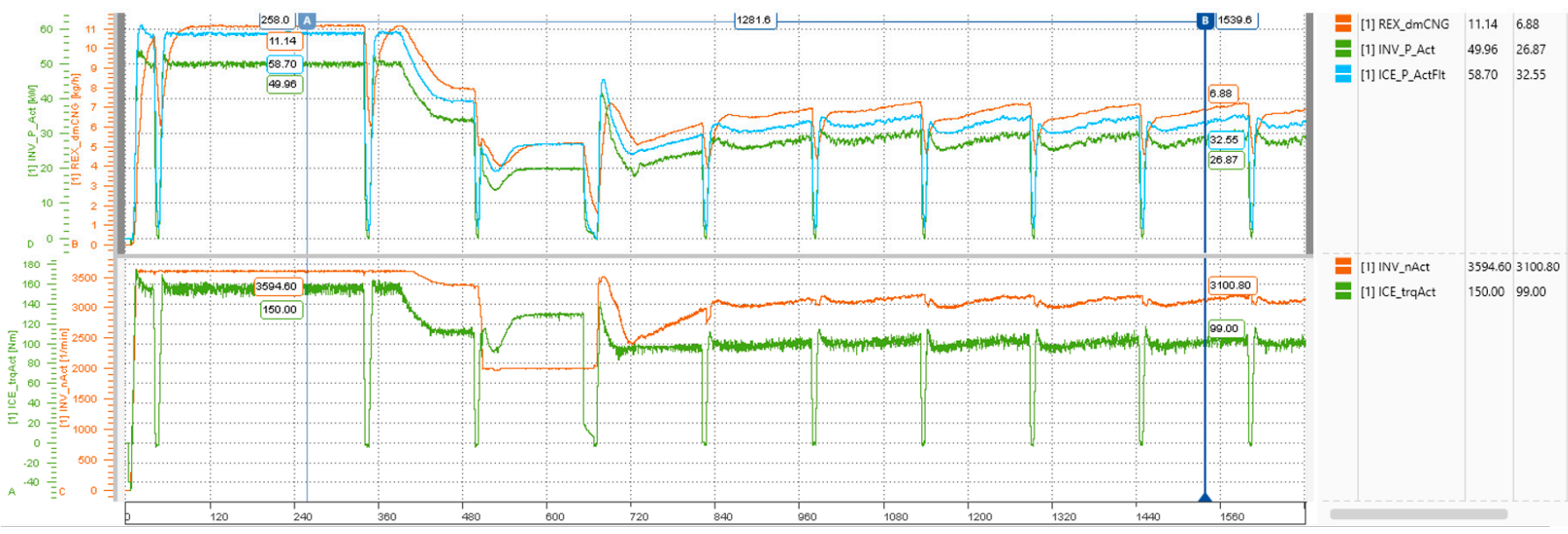

Figure 6. REx operation on a test bench: speed, torque, gas consumption and generated electric power.

\subsubsection{REx Module Efficiency}

The maximum power output (electric) of $50 \mathrm{~kW}$, for which the REx module was designed, is the setpoint in the first $360 \mathrm{~s}$ (values at point A). The efficiency here is $4.5 \mathrm{kWh} / \mathrm{kg}$ CNG or $34 \%$ (based on a calorific value of $13.2 \mathrm{kWh} / \mathrm{kg}$ for CNG). The combustion of $1 \mathrm{~kg}$ of $\mathrm{CNG}$ produces $275 \mathrm{~kg}$ of $\mathrm{CO}_{2}$, so the efficiency related to $\mathrm{CO}_{2}$ is $1.6 \mathrm{kWh} / \mathrm{kg} \mathrm{CO}_{2}$. A lower setpoint with advantages regarding acoustics and temperatures is shown with point B. Here, $27 \mathrm{~kW}$ of electric power was generated with $3.9 \mathrm{kWh} / \mathrm{kg} \mathrm{CNG}(30 \%)$ or $1.4 \mathrm{kWh} / \mathrm{kg} \mathrm{CO}$.

In Figure 7, the REx module is set to be $50 \mathrm{~kW}$ electric output and the vehicle (empty, no waste collector) is running on the test track between $45-65 \mathrm{~km} / \mathrm{h}$. In this $6 \mathrm{~min}$, the REx produces electric energy of $5 \mathrm{kWh}$ with about $1.1 \mathrm{~kg}$ CNG, which confirms the results from the test bench. 

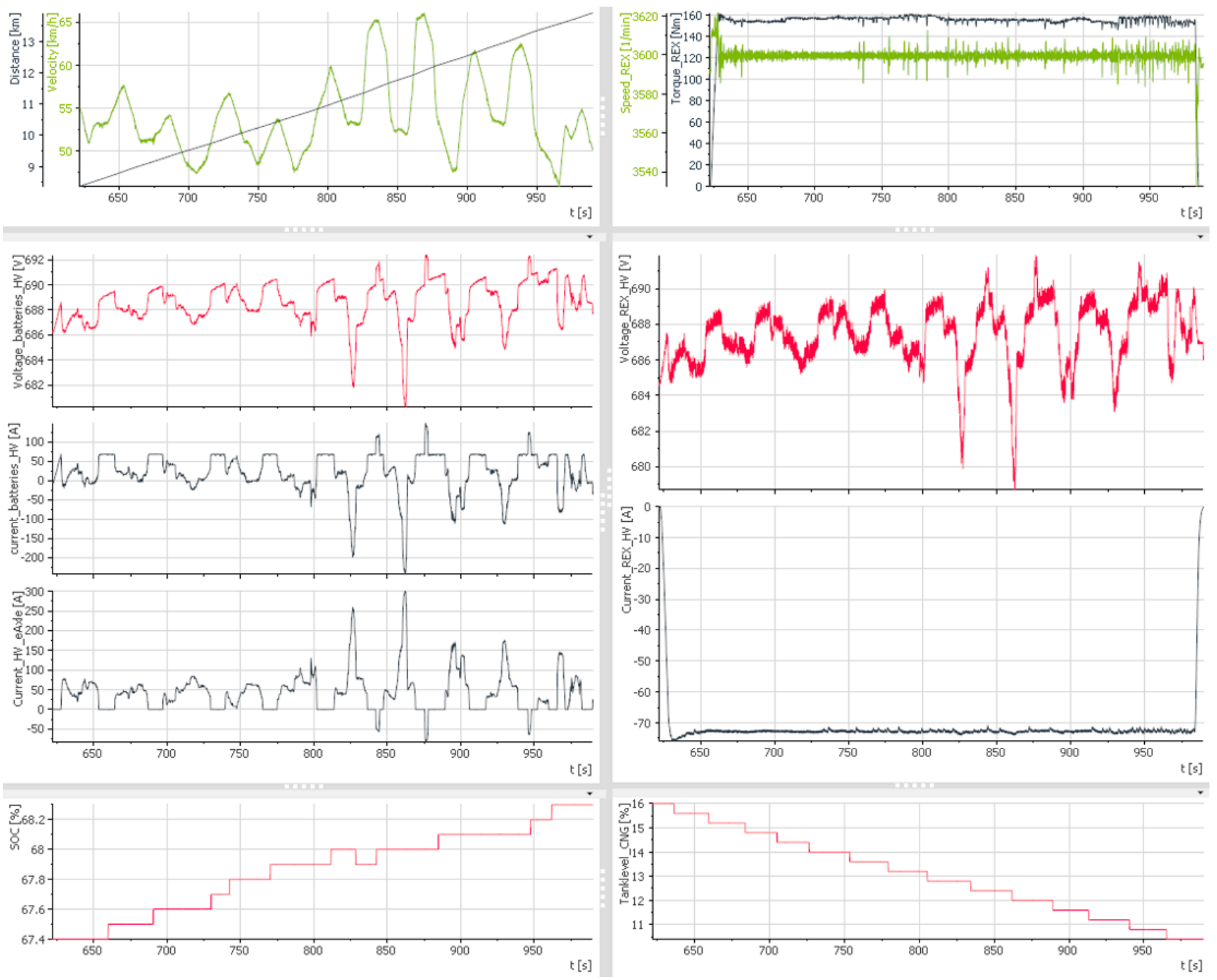

Figure 7. Vehicle operation in REx mode.

\subsubsection{Consumption}

The heat pump (heating, cooling, air conditioning) could be successfully put in operation. First exemplary runs show its potential to reduce energy consumption compared to a conventional electric heater. At $5^{\circ} \mathrm{C}$ ambient temperature, the cabin gets heated with an electric heater or the heat pump. Air temperatures in the cabin are identical, but the energy consumption of the heat pump is about half that of the electric heater in this setpoint and under these boundary conditions.

In terms of impact of energy consumption due to heating system, the E-Truck could be compared to an EB. The obtained results are consistent with those obtained from a real test that was conducted on the $12 \mathrm{~m}$ EBs in winter that were aiming to investigate the impact of the heating system on the EBs' range. The EBs were heated by an auxiliary fossil fuel heater that consumes energy of $110.5 \mathrm{kWh}$ plus $20 \mathrm{~L}$ of fuel to $144 \mathrm{kWh}$ plus $6.4 \mathrm{~L}$ of fuel. The EBs energy consumption with full-electric heating, "diluted" over $100 \mathrm{~km}$, stands in the range of 179-235 kWh. In other words, the energy consumed by the tested EBs is in the range of 1-1.4 kWh/km with fossil-fueled heating systems, while the consumed energy is up to $2.35 \mathrm{kWh} / \mathrm{km}$ with electrical heating systems. Taking Solobus as an example, with $300 \mathrm{kWh}$ of battery capacity, the range of the EB is between $214-300 \mathrm{~km}$ if heated using diesel and as low as $130 \mathrm{~km}$ if heated using electricity [6].

The graphs in Figure 8 show the voltage, current, SoC of the battery system, and charging power. Due to the CCS2 charging interface, the current is limited to $200 \mathrm{~A}$. With 
increasing battery voltage above $715 \mathrm{~V}$ (around $72 \% \mathrm{SoC}$ ), the charging current gets derated. At this point, the maximum charging power of about $143 \mathrm{~kW}$ is reached.

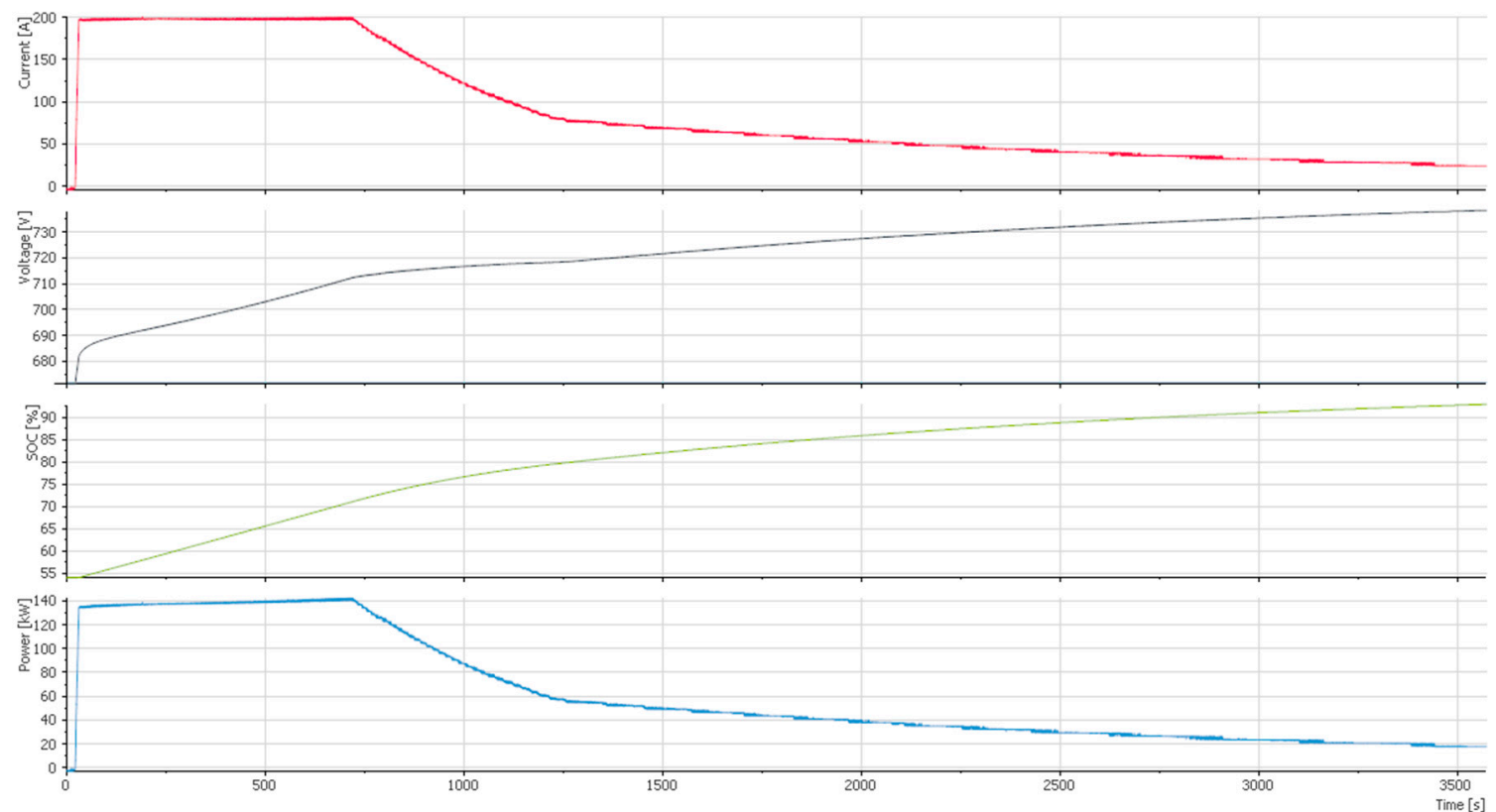

Figure 8. Voltage, current, state of charge and charging power while DC charging (CCS2 interface).

\section{Conclusions}

The interoperability between fast-charging technologies and EBs that were developed within the ASSURED project has been investigated. The tests showed that there is good compatibility between the two technologies, which, when the EBs working normally, minimizes the total system cost, minimizes the total infrastructure cost, and minimizes the number of chargers. Furthermore, the charging efficiency of the chargers reaches $99 \%$, which makes them technically and economically valuable. The fast-charging solutions proved their ability to meet the energy need of the EBs with optimized operation, which include deploying same number of EBs as diesel ones, no impact on the vehicle schedule, and the ability to use low battery capacity onboard.

The average energy consumption of EBs operating in the considered route lines have been estimated in order to investigate the possible locations and sizes of the charging systems that will need to be installed. The weather conditions were taken into account. It was found that some of the EBs consume extra $64 \%$ of power during the wintertime due to the heating system. It was proved, during the E-Truck demos operation, to optimize the energy consumption, that the heat pump consumes around half as much energy as the electric heater. This conclusion was taken from only one setpoint under specific boundary conditions during the testing and application of a heat pump. The heat pump could be used instead of electric heaters to minimize the total energy consumption. The energy consumption could be different for the same EBs with the same length, capacity, load condition, etc. This could be explained by the difference in traffic conditions (or terrain) from one line to another or from one city to another. In urban areas, the EB spends much time stopping and moving at low speeds, it consumes energy even when it is stopped in a traffic jam because it has to supply the auxiliaries.

Author Contributions: All authors have equal contribution. All authors have read and agreed to the published version of the manuscript.

Funding: This research was funded by the European Commission-Innovation and Networks Executive Agency, grant number 769850, under the title of ASSURED-H2020-GV-2016-2017/H2020-GV-2017. 
Institutional Review Board Statement: Not applicable.

Informed Consent Statement: Not applicable.

Data Availability Statement: Not applicable.

Acknowledgments: The VUB authors would also like to acknowledge Flanders Make for their support.

Conflicts of Interest: The authors declare no conflict of interest.

\section{References}

1. Smadi, A.; Hussein, M. Electric Bus in Mena; UITP MENA Centre for Transport Excellence: Dubai, United Arab Emirates, 2020; Available online: http:/ /library.fes.de/pdf-files/bueros/amman/17182.pdf (accessed on 1 November 2020).

2. Nádasi, R.; Tóth, C.; Balog, P. Towards the inductive on-road charging system for electric buses: Inspection of the Hungarian electric mobility fleet. Transp. Res. Procedia 2019, 41, 380-394. [CrossRef]

3. Position Paper-Heavy-Duty Vehicles: Charging and Refuelling Infrastructure Requirements. Available online: https://www. acea.auto/publication/position-paper-heavy-duty-vehicles-charging-and-refuelling-infrastructure-requirements/ (accessed on 21 May 2021).

4. Mohamed, M.; DaSilva, L. Optimizing electric bus transit systems: A review of modelling techniques and methods. In Proceedings of the 55th Annual Canadian Transportation Research Forum, Montreal, QC, Canada, 24-27 May 2020.

5. $\quad$ Lin, Y.; Zhang, K.; Shen, Z.-J.M.; Miao, L. Charging network planning for electric bus cities: A case study of Shenzhen, China Sustainability 2019, 11, 4713. [CrossRef]

6. He, Y.; Song, Z.; Liu, Z. Fast-charging station deployment for battery electric bus systems considering electricity demand charges. Sustain. Cities Soc. 2019, 48, 101530. [CrossRef]

7. Longo, M.; Leone, C.; Lorenz, L.; Strada, A.; Yaici, W. Electrification of a bus line in savona considering depot and opportunity charging. Adv. Sci. Technol. Eng. Syst. J. 2021, 6, 213-221. [CrossRef]

8. ASSURED. Available online: https:/ / assured-project.eu/ (accessed on 1 November 2017).

9. Jema Energy to Supply 11 Charging Systems for the First 100\% Electric Line in Vitoria-Gasteiz. Available online: https: / / assured-project.eu/news-and-events/news/jema-energy-to-supply-11-charging-systems-for-the-first-100-electricline-in-vitoria-gasteiz (accessed on 13 August 2019).

10. Electric Bus Range, Focus on Electricity Consumption. A Sum-Up. Available online: https://www.sustainable-bus.com/news / electric-bus-range-focus-on-electricity-consumption-a-sum-up/ (accessed on 20 March 2020).

11. Al-Saadi, M.; Patkowski, B.; Zaremba, M.; Karwat, A.; Pol, M.; Chełchowski, L.; Van Mierlo, J.; Berecibar, M. Slow and fast charging solutions for li-ion batteries of electric heavy-duty vehicles with fleet management strategies. Sustainability 2021, 13, 10639. [CrossRef]

12. Liu, Y.; Yao, E.; Lu, M.; Yuan, L. Regional electric bus driving plan optimization algorithm considering charging time window. Math. Probl. Eng. 2019, 2019, 7863290. [CrossRef]

13. Houbbadi, A.; Trigui, R.; Pelissier, S.; Redondo-Iglesias, E.; Bouton, T. Optimal scheduling to manage an electric bus fleet overnight charging. Energies 2019, 12, 2727. [CrossRef]

14. Haidl, P.; Buchroithner, A.; Schweighofer, B.; Bader, M.; Wegleiter, H. Lifetime analysis of energy storage systems for sustainable transportation. Sustainability 2019, 11, 6731. [CrossRef]

15. Available online: https://www.heuliezbus.com/fr/GX-ELEC (accessed on 8 March 2018).

16. Gong, J.; He, J.; Cheng, C.; King, M.; Yan, X.; He, Z.; Zhang, H. Road Test-Based Electric Bus Selection: A Case Study of the Nanjing Bus Company. Energies 2020, 13, 1253. [CrossRef] 